\title{
Recurrence of borderline ovarian tumors: a survival analysis
}

\author{
Sahana Punneshetty ${ }^{1}$, Anitha Thomas ${ }^{1}$, Dhanya Susan Thomas ${ }^{1}$, Rachel George Chandy ${ }^{1}$, \\ Sherin Daniel $^{2}$, Sharon Milton ${ }^{2}$, Abraham Peedicayil ${ }^{1}$, Ajit Sebastian ${ }^{1 *}$
} ${ }^{1}$ Department of Gynaecologic Oncology, ${ }^{2}$ Department of Pathology, Christian Medical College, Vellore, Tamil Nadu,
India

Received: 14 August 2021

Accepted: 06 September 2021

\section{*Correspondence:}

Dr. Ajit Sebastian,

E-mail: sebastian.ajit@gmail.com

Copyright: (c) the author(s), publisher and licensee Medip Academy. This is an open-access article distributed under the terms of the Creative Commons Attribution Non-Commercial License, which permits unrestricted non-commercial use, distribution, and reproduction in any medium, provided the original work is properly cited.

\section{ABSTRACT}

Background: Borderline ovarian tumors are non-invasive tumors that display greater epithelial proliferation and cytological atypia than benign tumors, but less than carcinomas. They may be treated conservatively in young women, however there is a concern for recurrence and progression to frank malignancy. We aimed to study the clinicopathological features of borderline ovarian tumors and their risk of recurrence.

Methods: We reviewed the electronic and paper charts of all borderline ovarian tumors operated between January 1, 2001 and December 31, 2019 at a tertiary level teaching hospital in India. Descriptive statistics such as proportions and means were used. A survival analysis was done for recurrence and death.

Results: A total of 93 borderline ovarian tumor patients were identified. The most common histology in our study was mucinous $60(63 \%)$ followed by serous $28(29 \%)$. Ninety two (99\%) of them were stage I at diagnosis. Microinvasion was present in $27(26 \%)$ of the cases. Out of the 30 fertility sparing operations performed (unilateral salpingooophorectomy/cytectomy), 4 (13\%) had recurrences and progressed to malignancy. The overall malignancy rate was $4 \%$. There was one mortality secondary to septic shock.

Conclusions: Borderline ovarian tumors account for 10-20\% of ovarian epithelial tumors and have extremely good prognosis affecting majorly the reproductive aged women. The low recurrence rate and good five year survival rate, at all the stages of the disease enables to incorporate fertility sparing surgeries as part of the staging.

Keywords: Adenocarcinoma, Borderline tumor, Recurrence

\section{INTRODUCTION}

Borderline ovarian tumors (BOT) were initially described by Howard Taylor in 1929. These tumors were classified by WHO in 1973 as low malignant potential tumors of the ovary and eventually recognized as a separate entity by the World Health Organization from 2003. They represent 10$20 \%$ of all epithelial ovarian tumors and have a good prognosis. ${ }^{1}$ The five year survival approaches $90 \%$ for all stages of BOTs. They commonly affect reproductive and premenopausal women and are usually unilateral. Presence of microinvasion and invasive implants increase the risk of recurrence and progression to invasive carcinoma. The ten year survival by stages are: stage I:
99\%, stage II: $98 \%$, stage III: $96 \%$, stage IV: $77 \%$. The purpose of the study was to analyse the clinicopathological features of borderline ovarian tumors and their risk of recurrence.

\section{METHODS}

The study was a retrospective observational cohort study, conducted at a Christian Medical College, Vellore, Tamil Nadu, India.

\section{Patient selection}

Electronic medical records of all the patients with diagnosis of borderline ovarian tumors, operated between 
$1^{\text {st }}$ January 2011 and $31^{\text {st }}$ December 2019 in the department of Gynaecologic Oncology were included. The patients' baseline characteristics like age, parity, body mass index, symptoms, co-morbidities, serum tumor markers and radiological findings were extracted. Operative details, frozen section report and post-operative diagnosis were also recorded. The follow up information was obtained from medical records as well as by telephone.

\section{Ethics}

The study protocol was reviewed and approved by Institutional Review Board, Research Ethics Committee, Christian Medical College, Vellore. The consent was waived off as this was a retrospective data.

\section{Statistics}

Statistical analyses was performed using SPSS version 21 software (SPSS for Mac Inc., Chicago, IL, USA). Descriptive statistics such as frequencies, mean and standard deviation or median were used. Survival analysis for recurrence and death was done and Kaplan Meier curves plotted. Time to recurrence or death was calculated from the date of surgery and patients were censored at the last follow up.

\section{RESULTS}

A total of 101 patients with diagnosis of borderline ovarian tumors were identified from the records. Five patients were upgraded to malignancy, 3 patients turned out to be benign and 93 patients remained borderline ovarian tumor after final histopathological diagnosis. The mean age of the patients was 41 (14.4 SD). Majority $(63,67 \%)$ of them were premenopausal and parous $(70,75 \%)$ women. The most common symptoms were abdominal pain $(70 \%)$ and abdominal distension (43\%). The mean BMI was 24.08 . The demographic details are given in Table 1.

Table 1: Demographic distribution.

\begin{tabular}{|ll|}
\hline $\begin{array}{l}\text { Demographic characteristics of } \\
\text { the patients (N=93) }\end{array}$ & $\mathbf{N}(\%)$ \\
\hline Age & $41(14)$ \\
\hline Parity & $23(25)$ \\
\hline Nulliparous & $70(75)$ \\
\hline Parous & $30(32)$ \\
\hline Menopausal status & $65(70)$ \\
\hline Abdominal pain & $08(9)$ \\
\hline Dyspepsia & $09(10)$ \\
\hline Menstrual irregularity & $01(1.1)$ \\
\hline Dyspareunia & $09(10)$ \\
\hline Postmenopausal bleeding & $40(43)$ \\
\hline Abdominal swelling & $07(7.5)$ \\
\hline Weight loss & $24(4.8)$ \\
\hline BMI & \\
\hline
\end{tabular}

Ninety nine percent of the patients belonged to stage I with only one patient in stage III. The most common histology in our institution was mucinous $(60 \%)$ followed by serous (28\%) Table 2. Microinvasion was present in 27 (29\%) cases. Invasive implants was seen in one patient. All the patients were operated by laparotomy. Fertility sparing surgeries were performed among 30 patients, out of which 7 underwent cystectomy and 23 unilateral salpingooophorectomy. Appendectomy was performed among 41 patients (44\%) and all were reported to be of normal histology.

Table 2: Histopathology distribution.

\begin{tabular}{|lc|}
\hline Histopathology & N $(\%)$ \\
\hline Mucinous & $60(65)$ \\
\hline Serous & $28(30)$ \\
\hline Seromucinous & $1(1)$ \\
\hline Endometroid & $1(1)$ \\
\hline Clear cell & $1(1)$ \\
\hline Brenner & $2(2)$ \\
\hline
\end{tabular}

Four (13\%) patients recurred and progressed to malignancy among the fertility preserved patients, out of which three were of mucinous histology and one clear cell. The overall malignancy transformation rate among these tumors was 4\%. The mean survival for recurrence was 98 months (Figure 1).

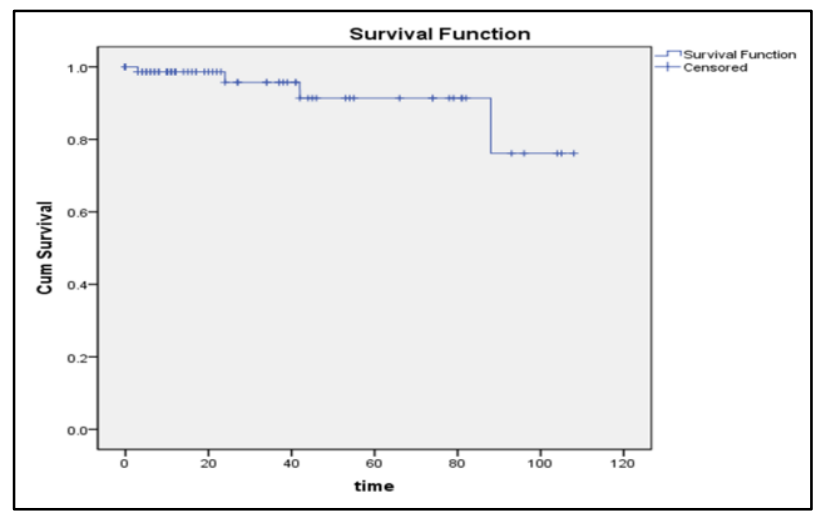

Figure 1: Survival curve for recurrence.

\section{DISCUSSION}

Borderline ovarian tumors (BOT) have good prognosis in all stages. Most of the cases usually present in stage I. They are characterized by atypical features in significant portion of the tumor and absence of stromal invasion. ${ }^{2}$ They represent $10-20 \%$ of ovarian malignancies and accounted for $10 \%$ in our institution. BOTs occur predominantly in premenopausal women. Surgery is the treatment of choice. Recurrence rates after fertility sparing surgery vary regardless of the surgical approach, whether it is ovarian cystectomy or oophorectomy with cystectomy, ranging from $23-58 \%$ and adnexectomy ranging from $0-20 \%{ }^{3}$ 
They present with non-specific symptoms varying from dyspepsia, abdominal fullness, flatulence, constipation and pain abdomen. The serum tumor marker CA 125 is elevated only in up to $50 \%$ cases and this indicates the presence of peritoneal implants at the time of diagnosis. ${ }^{4}$ Serum CA 125 was elevated in $16 \%$ of our patients.

The BOTs are classified as per revised WHO 2020 classification into serous, mucinous, clear cell, seromucinous and Brenner. Stromal microinvasion has been defined as invasion less than $5 \mathrm{~mm}$ in any single focus. Serous borderline tumors are not related to BRCA $1 / 2$ mutations. These tumors are typically cystic and generally more than $5 \mathrm{~cm}$ in size and are bilateral in one third of the cases. Microinvasion is seen in $10 \%$ of the cases. ${ }^{5}$ There are two types of peritoneal implant: non-invasive and invasive. Non-invasive implants can be epithelial or desmoplastic type, both carrying a similar prognosis. Invasive implants are the definitive poor prognostic factor. They progress to low grade serous carcinoma in up to 4$7 \%$ cases. ${ }^{6}$ In our study $30 \%$ of them had serous borderline ovarian tumors and one had invasive implant.

Mucinous borderline tumors are the second most common form of BOTs and the most common form in Asia comprising up to $70 \%$ of cases. ${ }^{7}$ They most often present with an abdominal mass and usually are unilateral. Adequate sampling of these tumor is crucial as they can harbor occult foci of carcinoma. These are either gastrointestinal/endocervical origin.

Immuno-profile shows typically CK 7 diffuse positivity with PAX 8 positive in $50-60 \%$ cases.

The recurrence rate with microinvasion is $5 \%$ and the tumour-related death rate is $5 \%$. Adverse behaviour is restricted to FIGO stage IC tumors. ${ }^{8}$ In our study, $65 \%$ had mucinous BOT and it was the most common BOT at our institution.

Endometroid borderline tumors account for 2-3\% of BOTs and usually present with a unilateral pelvic mass. Majority of the patients $(65 \%)$ have underlying endometriosis suggesting their origin. In addition, coexisting endometrial hyperplasia and/or carcinoma is common (39\%)..$^{9}$ These tumors have excellent prognosis. Clear cell variant comprises less than $1 \%$ of BOTs and usually affect postmenopausal women. They present with abdominal mass and are stage 1 at diagnosis. Endometriotic foci are often found in these tumors.

Sero-mucinous are uncommon and usually associated with endometriosis and has excellent prognosis. Brenners are composed of nests of transitional cell type epithelium, commonly affect elderly women. A solid area of benign Brenner tumor is always present. They show immunopositivity to p63 and GATA $3 .{ }^{10-12}$ They carry very good prognosis with local recurrences.
Surgery includes staging with unilateral oophorectomy (USO)/cystectomy/adnexectomy in young women desirous of fertility to total abdominal hysterectomy with bilateral salpingo-oophorectomy in women who have completed their family. The accuracy of frozen section varies from institution to institution and has generally above $70 \%$ accuracy. The recurrence rate overall is $12 \%$. If a cystectomy is performed, the recurrence rate is $23 \%$, compared to $8 \%$ with a USO. The median time to recurrence is 2.6 years after a cystectomy and 4.7 years after a USO ${ }^{14}$ Malignant transformation is observed in 20$30 \%$ of relapses. The role of lymphadenectomy is controversial.

We did laparotomy in all our cases. Thirty patients underwent fertility sparing surgeries and four had recurrence with malignant transformation. Out of the four recurrences, three were of mucinous histology and one was clear cell.

Adjuvant chemotherapy should be considered if there are invasive implants. The seven year overall survival of patients with non-invasive implants is $96 \%$ and with invasive implants is $66 \%$. There is an average $25 \%$ response rate for BOTs to chemotherapy. At second look, the response to chemotherapy was $15 \%$ if noninvasive implants were present, versus $57 \%$ if invasive implants were present, thus borderline tumors are not completely chemoresistant. ${ }^{15}$ The five and ten-year survival reach 95\% and $90 \%$ respectively. Prognosis is affected by many factors with major risk factor being stage, presence of invasive implants and residual disease.

\section{CONCLUSION}

BOTs are different from their malignant counterpart, with good prognosis and survival. The treatment is primarily surgical and follows the same directives as for malignant ovarian carcinomas. Fertility sparing surgery can be done in young women desiring pregnancy. Prognostic factors are stage, residual disease, invasive implants and micropapillary histology. Adjuvant chemotherapy should be considered if there are invasive implants. Long term follow-up is necessary, especially in women who underwent fertility sparing surgery or patients who presented with advanced disease.

\section{ACKNOWLEDGMENTS}

We acknowledge Dr. Nyengidiki T. Kennedy, a visiting observer from University of Port Harcourt Teaching Hospital, Nigeria for helping with data collection and $\mathrm{Mr}$. Richard for helping with statistical analysis.

Funding: No funding sources Conflict of interest: None declared

Ethical approval: The study was approved by the Institutional Ethics Committee, Christian Medical College, Vellore- IRB number 13877 


\section{REFERENCES}

1. Markowska J. Borderline tumors of the ovary. In: Ayhan A, Reed N, Gultekin M, Dursun P, eds. Text book of Gynaecology. 3rd edn. Turkey: Guines Publishing; 2016:698-702.

2. Silverberg SG, Bell DA, Kurman RJ, Seidman JD, Prat J, Ronnett BM, et al. Borderline ovarian tumors: key points and workshop summary. Hum Pathol. 2004;35(8):910-7.

3. Cho JE. Adnexal mass evaluation: evaluation and treatment. In: Ayhan A, Reed N, Gultekin M, Dursun P, eds. Text book of Gynaecology. 3rd edn. Turkey: Guines Publishing; 2016:671-678.

4. Fotopoulou C, Schumacher G, Schefold JC, Denkert C, Lichtenegger W, Sehouli J. Systematic evaluation of the intraoperative tumor pattern in patients with borderline tumor of the ovary. Int J Gynecol Cancer. 2009;19(9):1550-5.

5. Singh N. Pathology of malignant and borderline ovarian tumors. In: Ayhan A, Reed N, Gultekin M, Dursun P, eds). Text book of Gynaecology. 3rd edn. Turkey: Guines Publishing; 2016:689-697.

6. Longacre TA, McKenney JK, Tazelaar HD, Kempson RL, Hendrickson MR. Ovarian serous tumors of low malignant potential (borderline tumors): outcomebased study of 276 patients with long-term $(\geq 5$-year) follow-up. Am J Surg Pathol. 2005;29:707-23

7. Khunamornpong S, Settakorn J, Sukpan K, Suprasert $\mathrm{P}$, Siriaunkgul S. Mucinous tumor of low malignant potential ("borderline" or "atypical proliferative" tumor) of the ovary: a study of 171 cases with the assessment of intraepithelial carcinoma and microinvasion. Int J Gynecol Pathol. 2011;30:218-30.

8. Kim KR, Lee HI, Lee SK, Ro JY, Robboy SJ. Is stromal microinvasion in primary mucinous ovarian tumors with "mucin granuloma" true invasion? Am J Surg Pathol. 2007;31:546-54.
9. Roth LM, Emerson RE, Ulbright TM. Ovarian endometrioid tumors of low malignant potential: a clinicopathologic study of 30 cases with comparison to well-differentiated endometrioid adenocarcinoma. Am J Surg Pathol. 2003;27:1253-9.

10. Cuatrecasas M, Catasus L, Palacios J, Prat J. (2009). Transitional cell tumors of the ovary: a comparative clinicopathologic, immunohistochemical, and molecular genetic analysis of Brenner tumors and transitional cell carcinomas. Am J Surg Pathol. 2009;33:556-67.

11. Esheba GE, Longacre TA, Atkins KA, Higgins JP. Expression of the urothelial differentiation markers GATA3 and placental S100 (S100P) in female genital tract transitional cell proliferations. Am J Surg Pathol. 2009;33:347-53.

12. Liao XY, Xue WC, Shen DH, Ngan HY, Siu MK, Cheung AN. p63 expression in ovarian tumours: a marker for Brenner tumours but not transitional cell carcinomas. Histopathology. 2007;51:477-83.

13. Wu CH, Mao TL, Vang R, Ayhan A, Wang TL, Kurman RJ, et al. Endocervical-type mucinous borderline tumors are related to endometrioid tumors based on mutation and loss of expression of ARID1A. Int J Gynecol Pathol. 2012;31:297-303.

14. Michelle BF, William-Browns MY, Crieghton EL, Gynecologic oncology handbook. 1st edn. United states of America: Demos Medical Publishing; 2013.

15. Gershenson DM, Silva EG, Tortolero-Luna G, Levenback C, Morris M, Tornos C. Serous borderline tumors of the ovary with noninvasive peritoneal implants. Cancer. 1998;83(10):2157-63.

Cite this article as: Punneshetty $\mathrm{S}$, Thomas A, Thomas DS, Chandy RG, Daniel S, Milton S, et al. Recurrence of borderline ovarian tumors: a survival analysis. Int J Reprod Contracept Obstet Gynecol 2021;10:3856-9. 